\title{
Social Media wirken wie Suchtmittel
}

Bereits ein siebentägiger Verzicht auf Social Media wie Facebook und WhatsApp reicht in vielen Fällen aus, Entzugserscheinungen zu erzeugen, wie sie auch Suchtmittel verursachen, so das Ergebnis einer Studie österreichischer Wissenschaftler.

Social Media sind für sehr viele Menschen Teil ihres Sozialverhaltens und damit ihres Alltags geworden. Wenig weiß man jedoch über die Reaktion solcher Nutzer auf eine Abstinenzphase. Wie sehr fehlt innen die Nutzung - und was sind die Konsequenzen eines solchen Entzugs? Genau diesen Fragen sind zwei Wissenschaftler der Karl Landsteiner Privatuniversität Krems und der Universität Wien, nachgegangen und fanden aus der Suchtforschung bekannte Antworten, welche im Journal "Cyberpsychology, Behavior and Social Networking"veröffentlicht wurden [1].

An der Studie nahmen 152 Personen im Alter von 18 bis 80 Jahren teil, davon $70 \%$ Frauen. Über 1000 Personen erhielten die Einladung zur Teilnahme, nur ca. $30 \%$ zeigten Interesse und nur knapp $15 \%$ erklärten sich zur Social Media-Abstinenz bereit. Somit liegt die Vermutung nahe, dass sich eher Personen meldeten, denen der Verzicht auf Social Media leichter fällt und die Entzugserscheinungen dadurch eher milder ausfielen. Die Auswirkungen könnten daher für andere Personen noch ausgeprägter sein, so die Studienautoren.

》) Schon ein kurzer Social MediaVerzicht führt zu Entzugserscheinungen

Tatsächlich konnten klassische Entzugserscheinungen wie ein deutlich gesteigertes Verlangen, Langeweile sowie ein Einfluss auf positive und negative Stimmungslagen iden-

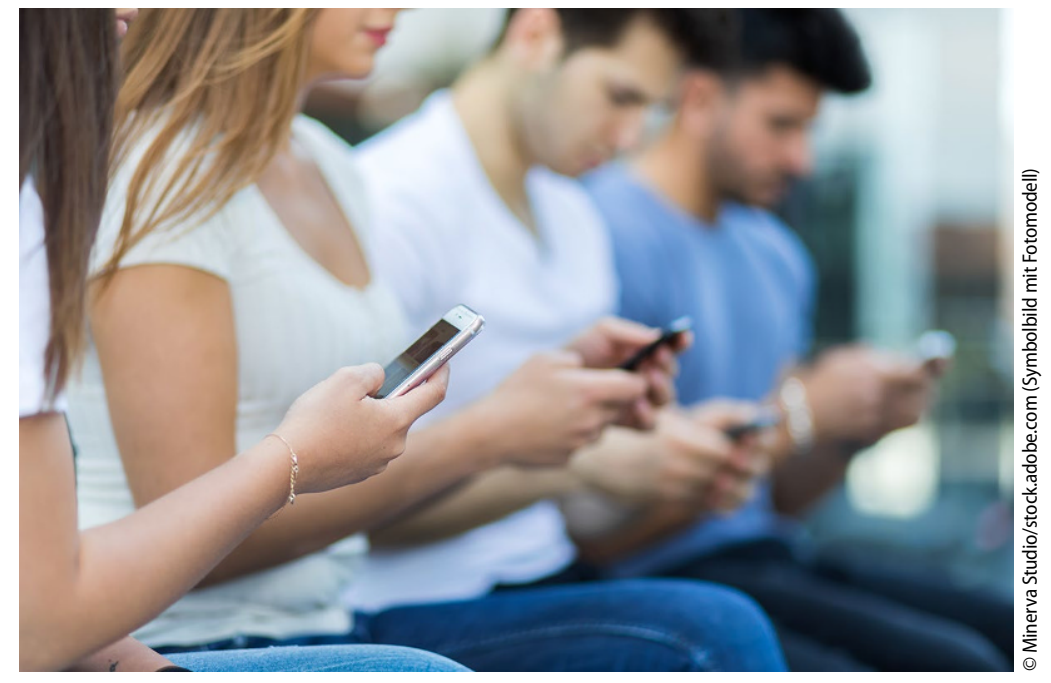

tifiziert werden. Eine intuitive Vermutung widersprechende Beobachtung machten Wissenschaftler bei den Auswirkungen auf die Stimmung der Probanden. Es fiel auf, dass bei einigen Probanden nicht nur das Empfinden positiver Stimmungen - erwartungsgemäß - vermindert wurde, sondern auch das Erleben negativer sich reduzierte. Das war unerwartet und entspricht nicht den klassischen Entzugserscheinungen, die ein stärkeres (!) Empfinden negativer Stimmung erwarten lassen würden.

\section{Abhängigkeit und Entzugserschei- nungen}

Am überraschendsten war jedoch, dass 90 von 152 Teilnehmern es nicht einmal schafften, die sieben Tage Social Media-Abstinenz durchzuhalten, ohne „rückfällig“ zu werden und - zumindest kurz - etwa ihre WhatsApp Nach- richten zu checken. Das Empfinden eines signifikant gesteigerten sozialen Drucks war vorhanden, obwohl den Probanden erlaubt war andere Kommunikationskanäle wie SMS, E-Mail und Telefonate zu nutzen. Dass bereits ein kurzfristiger Verzicht zu klassischen Entzugserscheinungen führt, wie sie auch Suchtmittel verursachen, überraschte die Wissenschaftler doch.

\section{Literatur \\ 1. Stieger S, Lewetz D (2018) A week without using social media: Results from an ecolo- gical momentary intervention study using smartphones. Cyberpsychology, Behavior, and Social Networking. 21:618-624.}

psychopraxis. neuropraxis 2019 $\cdot 22: 12$ https://doi.org/10.1007/s00739-0190544-0

C Springer-Verlag GmbH Austria, ein Teil von Springer Nature 2019 